\title{
Preconceito e estereotipação na tradição literária ibérica: cantigas galego-portuguesas
}

\author{
Ulisses de Oliveira \\ [Recibido, 15 xaneiro 2018; aceptado, 22 marzo 2018] \\ http://dx.doi.org/10.15304/bgl.52.4467
}

RESUMO A literatura tem sido especialmente importante na construção do pensamento e desenvolvimento humano. Partindo dessa perspectiva, a ideologia é uma dimensão contextual de ordem superior que está diluída no texto literário e, ao mesmo tempo, é construída pelo gênio de autores ao longo dos séculos. Portanto, ao nos depararmos com um dilema ideológico como o surgimento, a mudança, a perpetuação e as consequências do preconceito e estereotipação em nossa sociedade, é natural questionar o papel da literatura na criação e recriação de paradigmas ideológicos fundantes. O presente artigo pretende apresentar um ideário inicial da tradição literária ibérica, refletido nas cantigas galegoportuguesas, para compreender a representação do preconceito e estereotipação na época e certa herança ideológica que influenciou autores até a contemporaneidade.

PALAVRAS-CHAVE: ideologia; cantigas galego-portuguesas; preconceito; estereótipo.

ABSTRACT Literature has been especially important in the construction of human thought and human development. From this perspective, ideology is a contextual dimension of a higher order that gets into the literary text and, at the same time, becomes shaped by the genius of authors throughout the centuries. Hence, when we face ideological dilemmas, such as the emergence, change, perpetuation and consequences of prejudice and stereotyping in our society, it is natural questioning the role of the literature in the creation and re-creation of foundational ideological paradigms. This article intends to present an initial set of ideas of Iberian literary tradition, reflected on the Galician-Portuguese songs, in order to understand the representation of prejudice and stereotipation at the time and certain ideological heritage that has influenced authors until the present time.

KEYWORDS: ideology, Galician-Portuguese chants, prejudice; stereotype. 


\section{Preliminares}

A história do surgimento, mudança, perpetuação e consequências do preconceito, estereotipação e discriminação em nossa história literária remonta há muitos anos atrás, ainda muito antes dos primeiros textos em língua portuguesa, os quais, certamente, dialogizaram com fontes e tradições literárias oriundas, principalmente, da tradição literária ocidental. Autores na tradição ibérica, ao longo dos anos, introduziram reflexões sociais, raciais, culturais e étnicas que erigiram um paradigma de consciência e reflexão acerca de temas importantes para o desenvolvimento humano. Nesse mesmo sentido, é fundamental analisar como e quando a literatura passou a apresentar personagens e temas que discutissem o indivíduo e suas alteridades, ou seja, questões vinculadas à fuga do padrão socialmente construído de 'normal'; mais especificamente, alteridades refletidas no corpo, pensamento e comportamento, as quais podem marginalizar o indivíduo em determinado contexto.

De fato, complexos ideológicos podem ser cristalizados em preconceito ${ }^{1}$ e estereótipos ${ }^{2}$, os quais são refletidos, construídos e criticados na literatura, uma vez que esta é ulteriormente um retrato da realidade e da psiquê humana. Segundo Figueira (2000: 16), algumas “obras têm sido objeto de muito estudo da Psicologia Social que, através de certas 'armadilhas' em suas narrativas, repassam preconceitos e estereótipos".

Diante deste quadro, o presente artigo propõe apresentar o desenvolvimento inicial de complexos ideológicos sobre alteridades na tradição literária ibérica com o objetivo de compreender a representação do preconceito e estereotipação na época e certa herança ideológica que influenciou autores até a contemporaneidade. Para tanto, busca analisar textos anteriores ao português arcaico, invadindo o universo das cantigas medievais galego-portuguesas. Tais cantigas e o movimento do trovadorismo construíram um "ideário inspirado na educação, ética, estética, cortesia e cavalaria do qual somos herdeiros" (De Oliveira, 2014: 34). Mais especificamente, apresentaremos uma

1 Segundo Allport (1962: 22), o preconceito "é uma atitude hostil ou preventiva a uma pessoa que pertence a um grupo, simplesmente porque pertence a esse grupo, supondo-se, portanto, que possui as características contestáveis atribuídas a esse grupo".

2 Com base em Harding (1968) e Jameson (1990, 1998), Brito e Bona (2014: 17) conceituam o estereótipo como "um 'tipo social', uma representação comum posta em larga circulação, mas que não necessariamente faz jus à realidade: ela existe somente enquanto representação social de um dado real". 
análise mais detalhada dos traços ideológicos subjacentes em uma produção do trovador português Estevão da Guarda e outra do trovador Estêvão Fernandes Barreto.

A proposta analítica deste estudo está amparada nos pressupostos teórico-metodológicos da teoria da avaliatividade (Martin, 2000); uma teoria que desenvolve a semântica da avaliação, permitindo determinar o posicionamento assumido por autores ao abordar temáticas sobre preconceito e estereotipação, bem como compreender o processo de construção de paradigmas ideológicos. Neste estudo, contudo, daremos enfoque somente a alteridades de preconceito e estereotipação, conforme discutiremos na seção seguinte, uma vez que temas como, por exemplo, o papel da mulher na sociedade, homossexualismo e antissemitismo são temas de grande importância e abrangência e, portanto, cada qual mereceria um estudo aprofundado individualizado.

\section{As alteridades no esteio do preconceito e da estereotipação}

Emergido no berço da filosofia, o termo alteridade (lat. alteritas, 'outro') imbrica a concepção do pressuposto básico de que todo o ser humano social interage e interdepende do outro (Laplatine, 2003). Assim, na perspectiva das ciências sociais, a alteridade é a capacidade de se colocar no lugar do outro na relação interpessoal (família, trabalho, lazer, etc), com consideração, identificação e diálogo com seu semelhante. Portanto, a alteridade não pressupõe a existência de uma concordância, mas sim de uma aceitação de ambas as partes.

Do ponto de vista filosófico, a alteridade foi investigada por uma série de estudiosos que a conceberam na exata relação do ser humano com o seu 'semelhante', contrapondo suas diferenças. Alteridade é o contrário de identidade para Platão (em O Sofista, Marques, 2006). O autor rejeita a identificação do ser como identidade e vê um atributo do ser na multiplicidade das ideias, entre as quais existe a relação de alteridade recíproca. Já Sartre (1946: 6), concebe o homem como, antes de qualquer coisa, um projeto

que se vive subjetivamente, nada existe anterior a este projeto. Ele será o que ele tiver projetado e não o que ele quiser ser. Para isso, é necessário destacar que há dois tipos de subjetivismo: a escolha do sujeito individual por si só; e o outro a impossibilidade para o homem superar a subjetividade humana. 
Essa subjetividade humana mencionada por Sartre, e que também nos diferencia, foi expandida nos estudos sociológicos que popularizaram o termo alteridade. Tzvetan Todorov, em seu livro A conquista da América: a questão do outro (1983), retoma o vocábulo ao discutir a conquista da América e o reflexo do modo de agir e pensar dos europeus na época, que impuseram às sociedades ameríndias os seus valores como o correto e o modelo a ser seguido pelos outros.

A literatura, a partir dos estudos heglelianos, consolidaram o conceito de alteridade que assumimos neste trabalho. Para o autor, a alteridade designa o 'qualquer coisa', o ser determinado qualitativamente. A relação de negatividade com o 'outro' associa a alteridade a questões vinculadas à fuga do padrão socialmente construído de 'normal'. Daí, considerar-se o preconceito e o estereótipo como instanciações de alteridades refletidas no corpo, pensamento e comportamento humano. A marginalização social passa a ser consequência da dicotomia entre identidade e alteridade, ao considerarmos que "as identidades são em parte, uma forma de controle social, uma vez que distinguem e reprimem a diferença, e impõem avaliações normalizantes” (Silva, 2010: 42.).

No intuito de determinar traços de desenvolvimento e cristalização dos complexos ideológicos enquadrados na temática de alteridade, com enfoque em preconceito e estereotipação, utilizaremos os pressupostos teórico-metodológicos fornecidos pela teoria da avaliatividade (Martin, 2000), que trata da semântica da avaliação e, assim, pode elucidar questões da avaliação qualitativa na valoração de alteridade. Apresentamos o referido arcabouço teórico a seguir.

\section{A Teoria da avaliatividade}

A avaliatividade (traduzida de appraisal) foi idealizada por Martin (2000) e desesenvolvida por colaboradores como: Iedema, Feez e White (1994), Christie e Martin (2005), Eggins e Slade (2005), Scherer, Schorr e Johnstone (2001), entre outros. Segundo Martin (2000: 145) "appraisal trata-se dos recursos semânticos usados para negociar emoções, julgamentos e apreciações, além disso, são recursos usados para ampliar e se comprometer com essas avaliações". O conceito foi criado para denominar todos os usos avaliativos da linguagem, incluindo aqueles nos quais falantes/escritores adotam visões 
particulares ou posicionamentos ideológicos. Portanto, a avaliatividade é um pressuposto teórico analítico que considera, desde os elementos da linguagem dentro da sentença, até os elementos do contexto, das atividades, dos papéis e relações, das formações discursivas e ideológicas da sociedade.

A ideologia, nesse tocante, vem a integrar uma dimensão contextual superior (Figura 1), uma vez que é uma unidade mais ampla do que o texto (Halliday, 1985: 5), ou seja, "uma instância real de linguagem em uso" (Fairclough, 2003: 3). Portanto, o contexto formata o discurso em visões particulares formuladas na linguagem em uso (Fairclough, 2003: 3).

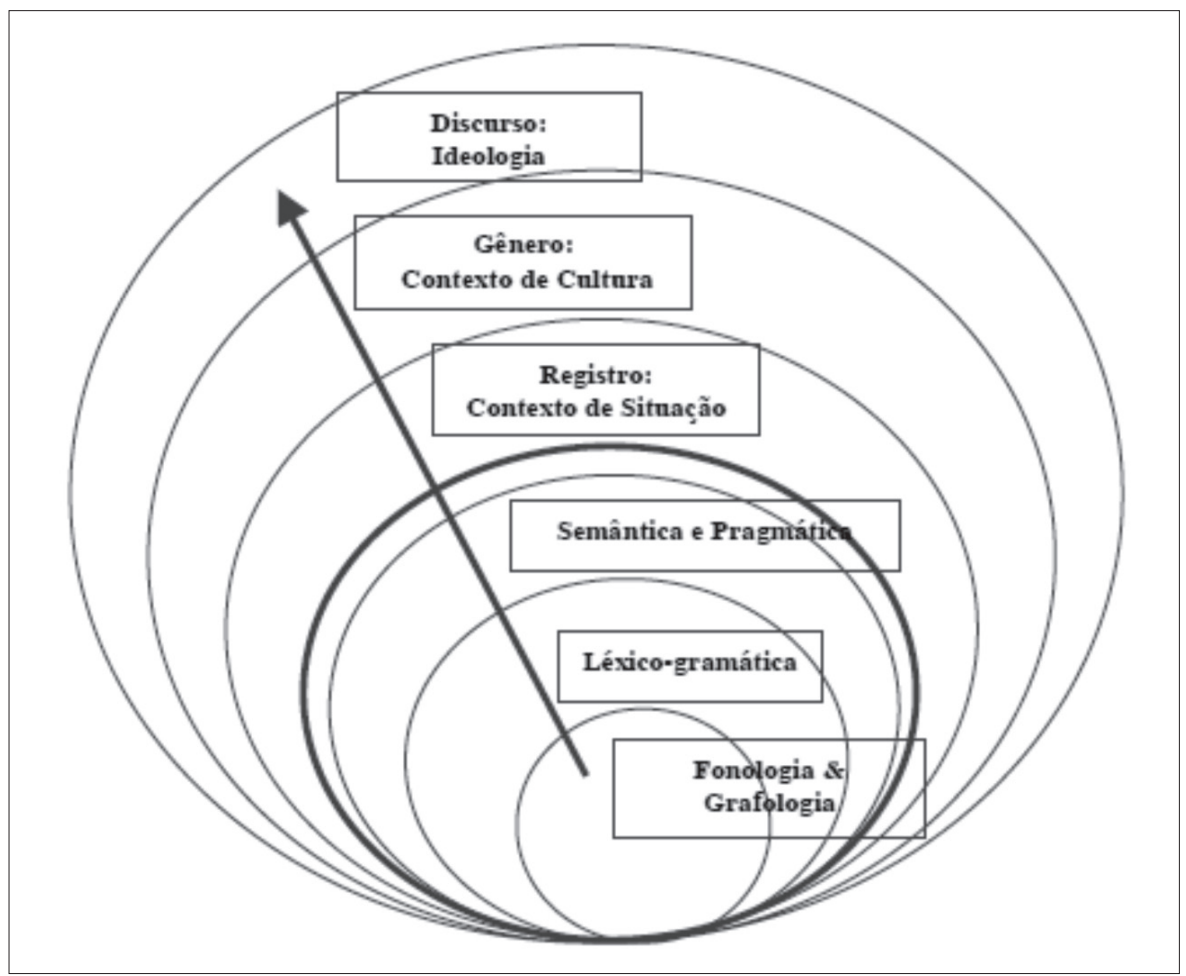

Figura 1. Articulação de conceitos do discurso como texto, interação e contexto. Fonte (adaptado de Martin, 1992: 496).

A Figura 1 se presta a uma analogia visual da noção de gênero. Na imagem, a flecha ascendente indica o mapeamento semântico, desde a instanciação da fonologia/grafologia, passando pela léxico-gramática, até a instanciação do discurso e da ideologia pelos contextos de registro (situação) e gênero (cultura). 
Ao considerar a semântica da avaliação no percurso mencionado, a avaliatividade considera três sistemas para os posicionamentos atitudinais: atitude, compromisso e graduação, todos tratando de valores interpessoais avaliativos de participantes e processos (conceitos centrais no sistema da transitividade que representa a experiência, Halliday, 1994). A atitude diz respeito a julgamentos de valores emocionais/afetuais dos interactantes. A atitude ainda é seccionada em três subsistemas, a saber, afeto, julgamento e apreciação. Martin (2000: 173) assim os define:

- O afeto analisa emoções canonicamente no enquadre grammatical, "eu sinto (muito) ' $x$ '...'. Exemplo: Eu sinto muita alegria/tristeza.

- O julgamento analisa atitudes sobre personagens, procurando sancionar ou censurar comportamentos canonicamente no enquadre grammatical, "Isso foi ' $x$ ' para ele/ela". Exemplo: Eu fui carinhoso/cruel com ele.

- A apreciação analisa atitudes sobre textos, performances e fenômenos naturais, e os adequa em enquadres do tipo "Eu considero isso ' $x$ '”. Exemplo: Eu considero isso inovador/sem imaginação.

O uso de uma teoria como da avaliatividade para a análise da ideologia é 26 relevante, pois ela revela a expressão das emoções pelo afeto e suas 'institucionalizações' (Martin, 2000: 147), isto é, “julgamento é afeto para controlar o comportamento (o que devemos ou não fazer) e apreciação é afeto recontextualizado para administrar 'gostos' (que coisas são piores ou melhores)" (De Oliveira, 2014: 62). Valores éticos e morais (regras e regulações) são alcançados pelo julgamento, enquanto valores estéticos (critério e quota) são alcançados pela apreciação.

Os outros dois subtipos de avaliatividade (compromisso e graduação) organizam a força/foco do enunciado e a noção de intersubjetividade pelo uso de bedgings (Hyland, 1998) utilizados para construir um posicionamento epistêmico, evidencialidade, intensidade e outras combinações. No presente estudo, discutiremos apenas a avaliatividade de atitude, pois a julgamos mais relevante para a argumentação proposta.

Há dois tipos básicos de avaliatividade: inscrita e evocada, que podem ocorrer separadamente ou combinadas. A inscrita torna a atitude explícita através de léxico e sintaxe avaliativos (epítetos, atributos relacionais ou adjuntos de comentário). A avaliação é explicitamente apresentada por meio de um item lexical carregado desse tipo de valor, por exemplo, 'habilmente', 
'corretamente', 'preguiçoso', etc. Já a avaliatividade evocada ocorre por enriquecimento lexical de algum tipo, como por exemplo a linguagem figurada (Martin, 2000). Nessas realizações, os valores são desencadeados pelo que pode ser visto como um simples 'fato', isto é, descrições aparentemente não avaliadas de algum evento ou estado de coisas. $\mathrm{O}$ ponto é que esses significados aparentemente 'factuais' ou informacionais, no entanto, têm a capacidade, na cultura, de evocar respostas de valoração. Assim, um comentarista pode inscrever um valor de julgamento de capacidade negativa acusando o governo de 'incompetente', ou, alternativamente, evocar o mesmo valor por meio de um sinal como 'o governo não estabeleceu as bases para o crescimento a longo prazo'.

Antes de aplicar os pressupostos da avaliatividade, as próximas seções discutem as cantigas galego-portuguesas e sua tradição literária e, mais especificamente, os temas de preconceito e estereotipação naquele contexto.

\section{A tradição literária das cantigas galego-portuguesas}

O galego-português foi a língua falada durante a Idade Média em diferentes regiões da Península Ibérica, especialmente em Portugal e na Galiza. Embora haja dissensão sobre a matéria, de acordo com alguns autores (por exemplo, Sansone e Furtado, 2014), o galego-português é considerado $\mathrm{o}$ ancestral comum mais proeminente de algumas línguas peninsulares, entre elas o português e o espanhol. A língua floresceu a partir do século VIII, principalmente na literatura, por ter se tornado a língua da poesia e da arte nos reinos da Galiza, Portugal, Leão e Castela. Ao menos, não há dúvida de que a literatura portuguesa se originou na lírica galego-portuguesa, a qual foi considerada a segunda literatura mais importante durante a Idade Média na Europa Ocidental, só perdendo em difusão para a lírica occitânica (Sequeira, 1959). Tal literatura floresceu durante um período de cerca de 150 anos, que vai, genericamente, de finais do século XII a meados do século XIV.

A arte trovadoresca está compilada em três grandes cancioneiros (o Cancioneiro da Ajuda, o Cancioneiro da Biblioteca Nacional e o Cancioneiro da Vaticana); neles, estão reunidas cerca de 1680 cantigas profanas ou de corte, manuscritas, de cerca de 187 trovadores e jograis, e pertencentes aos gêneros cantiga de amor, amigo e escárnio e maldizer. 
A importância da investigação da cultura e da sociedade daquela época e região, por meio da lírica galego-portuguesa, é tamanha, que tal patrimônio cultural imaterial foi transformado pelos governos de Portugal e de Espanha em Masterpiece of Oral and Intangible Heritage of Humanity (2005).

\section{A representação de alteridades nas cantigas galego-portuguesas}

Algumas cantigas do colegiado dos três grandes cancioneiros -dentre as 1680 facsimiladas- são absolutamente significativas quanto à temática em foco no presente estudo. Tais produções são precursoras da representação de complexos ideológicos a respeito de alteridades no contexto ibérico, a saber:

- Duas cantigas tem o subtema defeitos físicos ("Em preito que Dom Foam há" e "Meu dano fiz por tal juiz pedir" de Estevam da Guarda);

- Dezoito cantigas apresentam o subtema doenças diversas ou ridicularizações associadas a aspectos físicos ou comportamentais ("Ao daiam de Cález eu achei” de Afonso X; "D’ũa cousa sõo maravilhado" de Pero Garcia Burgalês; "De Pero Bõõ and'ora espantado" de Pero Garcia de Ambroa; "Deus! Com'ora perdeu Joam Simiom”, "Disse-m'hoj'um cavaleiro", "Ou é Meliom Garcia queixoso" e "Tant'é Meliom pecador" de D. Dinis; "Dizem, senhor, que nom hei eu poder" de João Airas de Santiago; "Dom Estêvam, em grand'entençom" e "Dom Marco, vej'eu muito queixar" de Rui Queimado; "Dom Estêvam, que Lhi nom gradecedes" e "Quem diz de Dom "Stêvam que nom vê bem" de João Soares Coelho; "Estevam Eanes, por Deus mandade" de Estêvão Fernandes Barreto; "Domingas Eanes houve sa baralha" de Afonso X; "Joam Nicolás soube guarecer" de Airas Peres Vuitorom; "Nenguem-mim, que vistes mal doente" de Fernão Garcia Esgaravunha; "Um sangrador de Leirea” de Mem Rodrigues de Briteiros (provável, cf. Lapa, 1965); e "Vedes agora que mala ventura" de Vasco Peres Pardal.

A seguir, no Quadro 1, estão alguns detalhes sobre as principais cantigas que abordam temas de alteridades variadas e outros queixumes centrados em doenças diversas e ridicularizações de aspectos físicos ou comportamentais. Os códices CBN e CV são siglas para, respectivamente, o Cancioneiro da Biblioteca Nacional, edição de Machado e Machado (1949) e o Cancioneiro da Vaticana, edição de Braga (1878). 


\begin{tabular}{|c|c|c|c|c|}
\hline Autor & Códice(s) & Mote & Resumo & Excerto \\
\hline Affonso $X$ & $\begin{array}{l}\text { CBN 493, } \\
\text { CV } 76\end{array}$ & \begin{tabular}{|l|} 
Ataque ferino ao deão de Cádis \\
a respeito do seu gosto por livros \\
eróticos (árabes), aliado ao seu \\
pendor para a feitiçaria.
\end{tabular} & $\begin{array}{l}\text { Acusado de feiticeiro e fazer } \\
\text { curas milagrosas (em troca de } \\
\text { favores sexuais). }\end{array}$ & $\begin{array}{l}\text { wv. } 27,28 \\
\text { assi a fode per arte e per sem, / } \\
\text { que saca dela o demo malvaz. }\end{array}$ \\
\hline $\begin{array}{l}\text { Pero Garcia } \\
\text { Burgalês }\end{array}$ & $\begin{array}{l}\text { CBN 1372, } \\
\text { CV 980 }\end{array}$ & $\begin{array}{l}\text { Sobre a morte de um tal Pedro } \\
\text { Bom (de sorte desconhecida). }\end{array}$ & $\begin{array}{l}\text { A sátira reside na doença que } \\
\text { Ihe causava gases intestinais. }\end{array}$ & $\begin{array}{l}\text { wv. 5, } 6 \\
\text { e bem manceb'assaz pera viver, / e } \\
\text { foi doent'e nom se confessou, }\end{array}$ \\
\hline $\begin{array}{l}\text { Pero Garcia de } \\
\text { Ambroa }\end{array}$ & CBN 1575 & $\begin{array}{l}0 \text { mesmo mote da anterior, a } \\
\text { morte de um tal Pedro Bom. }\end{array}$ & $\begin{array}{l}\text { Joguete com o sentido do } \\
\text { verbo peer. peidar e dar } 0 \\
\text { último suspiro. }\end{array}$ & $\begin{array}{l}\text { w. 7, } 14 \\
\text { e, ante luz, acharom-no peideiro / iá } \\
\text { del mazela nunca prenderia! } \\
\end{array}$ \\
\hline D.Dinis & CBN 1540 & $\begin{array}{l}\text { Sátira a um cavaleiro, dado à } \\
\text { calúnia e à maledicência. }\end{array}$ & \begin{tabular}{|l|} 
cavaleiro doente se vê impelido \\
a engolir uma erva amarga (a \\
lorbaga) como laxante.
\end{tabular} & \begin{tabular}{|l|} 
w. 15,16 \\
mui doent'e mui nojoso \\
e com medo per si caga,
\end{tabular} \\
\hline $\begin{array}{l}\text { João Airas de } \\
\text { Santiago }\end{array}$ & $\begin{array}{l}\text { CBN 944, } \\
\text { CV 532 }\end{array}$ & Sátira e elogio à própria esposa & \begin{tabular}{|l|}
0 trovador faz um joguete \\
com sua própria miopia: "eu \\
vejo mal, mas, quando te vejo, \\
vejo bem."
\end{tabular} & $\begin{array}{l}\text { w. } 8,12 \\
\text { e dizem que nom vejo bem, senhor, } \\
\text { pois eu vos vejo, muito vejo bem. }\end{array}$ \\
\hline Rui Queimado & $\begin{array}{l}\text { CBN 1388, } \\
\text { CV } 997\end{array}$ & \begin{tabular}{|l|} 
Sátira que aborda o tema da \\
miopia ou cegueira, pela queixa \\
de um certo D. Marco a Dom \\
Estêvam \\
\end{tabular} & $\begin{array}{l}\text { A cantiga ressalta a miopia ou } \\
\text { cegueira de D. Estevam }\end{array}$ & $\begin{array}{l}\text { w. } 3,4,5 \\
\text { que, pero foi mui mal doent'aqui, / } \\
\text { que vos nunca quisestes trabalhar / } \\
\text { de o veer, nen'o vistes; mais bem } \\
\end{array}$ \\
\hline $\begin{array}{l}\text { Estêvão Fernandes } \\
\text { Barreto }\end{array}$ & $\begin{array}{l}\text { CBN 1611, } \\
\text { CV 1144 } \\
\text { (CV 1611) }\end{array}$ & $\begin{array}{l}\text { A rubrica da cantiga explica } \\
\text { geralmente seu contexto: um } \\
\text { cavaleiro supostamente leproso } \\
\text { (gafo) era perseguido por um } \\
\text { outro. }\end{array}$ & $\begin{array}{l}\text { Esta cantiga é a única } \\
\text { referência à lepra encontrada } \\
\text { nos cancioneiros galego- } \\
\text { portugueses. }\end{array}$ & $\begin{array}{l}\text { Rubrica: "Esta cantiga de cima fez } \\
\text { Stevam Fernándiz Barreto a um } \\
\text { cavaleiro que era gafo e morava em } \\
\text { Santarém; e soem a ir em romaria } \\
\text { a Santa Maria; a mão mâo dereita do } \\
\text { caminho estál logo a Triindade, e } \\
\text { estava logo a gafaria a par dela." }\end{array}$ \\
\hline Afonso $\mathrm{X}$ & $\begin{array}{l}\text { CBN 495, } \\
\text { CV } 78\end{array}$ & \begin{tabular}{|l|}
0 Rei Sábio satiriza uma \\
soldadeira, Domingas Eanes, a \\
qual, após vencer um cavaleiro \\
mouro num combate, teria saído \\
ferida pelo tragazeite (pequena \\
lança). Os médicos não puderam \\
fechar sua ferida. \\
\end{tabular} & \begin{tabular}{|l|} 
É certo que a ferida de \\
Domingas Eanes era aparente \\
e, segundo Resende de \\
Oliveira (2006), é de crer que \\
as fistulas provocadas pelas \\
feridas estivessem associadas a \\
alguma doença venérea. \\
\end{tabular} & $\begin{array}{l}\text { v. } 28 \\
\text { e por en muit'há que é fistolada. }\end{array}$ \\
\hline $\begin{array}{l}\text { Fernão Garcia } \\
\text { Esgaravunha }\end{array}$ & CBN 1510 & $\begin{array}{l}\text { Segundo Lapa (1970), a } \\
\text { cantiga descreve como o } \\
\text { trovador se gaba de ter curado } \\
\text { de uma grave doenca um tal } \\
\text { Nenguem-mim (alcunha). }\end{array}$ & $\begin{array}{l}\text { A tal doença grave parece ser } \\
\text { ironia. Lapa (1965) diz ser } \\
\text { alivio dos gases intestinais - a } \\
\text { cura - considerando o contexto } \\
\text { e o desejo do "doente" de } \\
\text { voltar a beber. } \\
\end{array}$ & $\begin{array}{l}\text { wv. } 1,13 \\
\text { Nenguem-mim, que vistes mal doente } \\
\text { estornudou tres peidos e guariu }\end{array}$ \\
\hline D. Dinis & CBN 1533 & $\begin{array}{l}\text { A sátira do Rei D.Dinis, ainda } \\
\text { jovem à época, está no jogo de } \\
\text { palavras "meninas" (meninas } \\
\text { dos olhos) e "catar" (ver), } \\
\text { com referência à cegueira de } \\
\text { Meliom Garcia. }\end{array}$ & $\begin{array}{l}\text { Lapa (1965) associa este } \\
\text { cantar à cantiga seguinte no } \\
\text { CBN (1534) para interpretar } \\
\text { o jogo de palavras que se } \\
\text { faz para tratar da cegueira/ } \\
\text { miopia do alvo das chufas. }\end{array}$ & $\begin{array}{l}\text { w. 3, } 4 \\
\text { escontra duas meninhas que trage, } \\
\text { contra que nom cata bem nem } \\
\text { fremoso: }\end{array}$ \\
\hline D. Dinis & CBN 1534 & $\begin{array}{l}0 \text { mesmo tema da cantiga } \\
\text { anterior (1533) }\end{array}$ & $\begin{array}{l}\text { Devido à cegueira, Meliom } \\
\text { Garcia está impossibilitado de } \\
\text { "ver a face de Deus". }\end{array}$ & \begin{tabular}{|l} 
w. 13,14 \\
que jamais nunca veerá \\
em nẽum temp'a face de Deus.
\end{tabular} \\
\hline
\end{tabular}

Quadro 1. Doenças diversas e ridicularizações de aspectos físicos ou comportamentais (Machado e Machado, 1949 e Braga, 1878).

3 Resende de Oliveira (1993a) entende que, pela referência a D. Marco, este Dom Estêvam não deve ser $D$. Estêvão Anes, o qual foi alvo de um ciclo de cantigas que também abordava o tema de alteridade que abordaremos adiante. 
Nota-se, na temática e versos das cantigas que, paralelamente ao sarcasmo zombeteiro característico das chufas palacianas, a rudeza dos tempos medievais deixa sua marca. Naqueles tempos, valores éticos ainda se fundavam, juntamente com as cidades e a própria organização social pré moderna. O modelo feudal estratificava a sociedade e, conforme Le Goff (1986: 12):

A sociedade medieval foi, mais do que muitas outras, uma sociedade de oposições e, se recusou o maniqueísmo doutrinal, praticou um maniqueísmo de facto através de oposições de tipo bons/maus, ou então, de tipo superior/inferior. A cristandade foi, assim, representada muitas vezes por esquemas binários, por pares antitéticos, sendo o mais geral, e o mais importante, a oposição clérigos/leigos.

Além dos pares antitéticos de fundo religioso que polarizavam grupos sociais, alguns aspectos e paradigmas foram construídos no seio da sociedade civil, dentre eles, aqueles que marginalizavam membros que apresentavam alteridades, tais como deficiências, doenças oftalmológicas, lepra, doenças venéreas, etc. Dado o fato de que a medicina ainda não existia como ciência estabelecida, portadores de doenças e deficiências tinham extrema dificuldade em sobreviver e se inserir socialmente. A expectativa de vida era baixa e há muitos relatos de abandonos e mortes induzidas para casos que demandavam tratamento e cuidados extensivos das famílias (Major, 1954).

A vida na Península Ibérica era rude - um contínuo campo de batalha principalmente durante a Reconquista. Diante desse quadro, um efeito social especialmente crítico ocorreu nas cidades, para onde muitos homens não retornavam das guerras, ou voltavam mutilados, cegos e doentes. Segundo Ceschin (2004), as cidades medievais eram povoadas por mulheres, velhos e doentes. A mendicância era uma alternativa comum, pricipalmente depois do crescimento das ordens religiosas mendicantes. Herculano (2014) narra sucessivas epidemias e, principalmente durante cercos, cenas de canibalismo e cadáveres em putrefação eram frequentes nas cidades. Não raro, invasores e representantes régios executavam doentes, mutilados e deficientes. Tal contexto foi propício para a marginalização social de mulheres, idosos, doentes, etc.

Com enfoque em alteridades, é natural que a rudeza dos tempos forjasse o espírito do homem e da mulher medieval, tal que alteridades passaram a também designar um grupo de pessoas que cresceu sob o estigma do abandono. À época, já existia uma tradição ideológica negativa a esse respeito, como exemplifica Aristóteles em seu Política, séculos antes: "quanto à exposição e 
criação de crianças, deve haver uma lei que nenhuma criança deformada viverá" (Aristóteles, em Reeve, 1998: 67).

Os cancioneiros registram também essa estereotipação pela própria antroponímia, pois a onomástica indica, embora em número reduzido, alcunhas de alteridade para identificar indivíduos. Para Vivas e Oliveira-Leitão (2008), "uma alcunha, pela sua própria natureza, pode servir para engrandecer ou denegrir o visado (desde adjectivos como ledo ou loução, a outros não tão favoráveis como gago, calvo ou velho)".

Para além da onomástica, o sabor retórico das cantigas apresentava uma crítica ainda mais mordaz ao portador de alteridade. Nesse sentido, a seguir, apresento análises pormenorizadas de duas cantigas, as quais trazem rubricas bem explicativas no manuscrito que identificam o alvo das críticas: um juiz manco (CBN, 1303; CV, 908) e um cavaleiro leproso (CBN, 1611; CV, 1144).

\section{Complexos ideológicos sobre alteridades nas cantigas de Estêvão da Guarda e Estêvão Fernandes Barreto}

As edições críticas realizadas na análise têm base no confronto dos manuscritos primários e em Lapa (1965) -(abrev. L.)-, seguidos de eventuais lições ou interpolações de Machado e Machado (1949) -(abrev. Mdo.)-, Lopes (2002) -(abrev. Lop.)- e Braga (1878) -(abrev. Br.)-, todas devidamente assinaladas em aparato crítico no rodapé. A análise da avaliatividade apresenta ocorrências de avaliação inscrita e evocada. Quando evocada, optamos por trazê-la acompanhada de breve nota explicativa.

A rubrica da cantiga de produção do trovador português Estevão da Guar$\mathrm{da}^{4}$ (CBN, 1303; CV, 908) diz: "Esta cantiga de cima foi feita a un meestre de

4 "Trovador português ativo no período final da poesia galego-portuguesa, Estêvão da Guarda deverá ter nascido por volta de 1280, muito provavelmente na cidade da Guarda, como o seu apelido indica. Em 1299 encontramo-lo já na corte de D. Dinis, desempenhando as funções de escrivão régio. Nos anos seguintes, e sobretudo a partir de 1314, a sua gradual proximidade com o rei, de quem se diz "vassalo" e "criado", é-nos comprovada quer pelos numerosos documentos que assina em seu nome, quer pelos cargos que acumula de eichão e escanção-mor, quer ainda pelas doações e benesses régias que the são conferidas em penhor da sua fidelidade e dos seus bons serviços, e que contribuíram para a importante fortuna que conseguiu acumular. [...] Após a morte de D. Dinis, no entanto, e embora o seu nome apareça de forma mais esporádica, continua a ser mencionado como conselheiro régio e procurador para os assuntos ibéricos de Afonso IV (Pizarro, 1999). Como uma parte das suas composições satíricas pode ser datada deste período, 
leis, que era manco d'ũa perna e çopegava dela muito." A crítica foi feita a um mestre de leis (juiz), caracterizado como inapto e manco (rubrica). A cantiga mostra uma demanda com outrem e se apoia num jogo de palavras centrado no verbo decaer, ou seja, a alegoria de cair (perder contenda judicial) e cair (no chão, devido ao referido problema na perna).

\begin{tabular}{|c|c|c|c|c|}
\hline & \multirow{2}{*}{ CBN 1303, CV $908^{5}$} & \multicolumn{3}{|r|}{ avaliatividade } \\
\hline & & Tipo & INSCRITOS & EVOCADOS \\
\hline$R$ & $\begin{array}{l}\text { Esta cantiga de cima foi feita } \\
\text { a un meestre de leis, que era } \\
\text { manco d'ũa perna e çopegava } \\
\text { dela muito. }\end{array}$ & $\mathrm{J} / \mathrm{J}$ & $\begin{array}{l}\text { (-) Epíteto - manco } \\
\text { (-) Epíteto - copegava }\end{array}$ & \\
\hline \multirow[t]{4}{*}{1} & Em preito que Dom Foam á, & $\mathrm{J}$ & & $\begin{array}{l}\text { (-) D. Fulano, forma usual que esconde uma identidade concreta. } \\
\text { Já caracteriza o alvo das críticas. }\end{array}$ \\
\hline & $\begin{array}{l}\text { com um meestre, há gram } \\
\text { castom; }\end{array}$ & $\mathrm{J}$ & (+) Epíteto - mestre & $\begin{array}{l}\text { (-) A polissemia é um recurso muito explorado no galego-português } \\
\text { Neste caso, o uso de caston (questão) e caston (castão, i.e. } \\
\text { bengala) faz alusão à manqueira do juiz. }\end{array}$ \\
\hline & e o meestre pressopom & \multirow[t]{3}{*}{$\mathrm{J}$} & \multirow{3}{*}{$\begin{array}{l}\text { (+) Comentário } \\
\text { (+) Epíteto - mestre }\end{array}$} & \multirow{3}{*}{$\begin{array}{l}\text { (-) Novamente o enriquecimento lexical. Explicitamente, lê-se "e } \\
\text { o mestre pensa que o direito lhe é tão desfavorável". Contudo, é } \\
\text { provável uma referência ao pé direito do mestre (torto = contrairo) }\end{array}$} \\
\hline & o de que o dereit'está & & & \\
\hline \multirow[t]{5}{*}{5} & tam contrairo, per quant'eu vi, & & & \\
\hline & que, se lh'outrem nom acorr'i, & \multirow[t]{2}{*}{$J$} & \multirow[t]{2}{*}{ (+) Epíteto mestre } & \multirow{2}{*}{$\begin{array}{l}\text { (-) Se outro não socorrê-lo disso (nesse caso, dado pelo clítico), } 0 \\
\text { mestre cairá. Referênncia implícita ao homem manco. }\end{array}$} \\
\hline & 0 meestre dequeerá. & & & \\
\hline & Mais, se decae, quem será & \multirow[t]{3}{*}{$\mathrm{J}$} & & \multirow{3}{*}{$\begin{array}{l}\text { (-) avaliação implíita e modalizada pela condicional e a introdução } \\
\text { da pergunta retórica que é a estrofe. Decai, sem direito e sem } \\
\text { razão e, se for procurar, nem defesa. }\end{array}$} \\
\hline & que já dereito nem razom & & & \\
\hline \multirow[t]{5}{*}{10} & for demandar nem defensom & & & \\
\hline & em tal meestre, que nom dá & $\mathrm{J}$ & \multirow[t]{4}{*}{ (+) Epíteto } & \multirow{4}{*}{$\begin{array}{l}\text { Na primeira leitura, de superfíicie: (quem pediria os servicos) de tal } \\
\text { mestre, que nem sabe defender-se nas suas próprias contendas, } \\
\text { mas terá de levar alguém que o ajude (jurídico). A segunda leitura } \\
\text { revela julgamento negativo implííito (-): o mestre não é capaz } \\
\text { de manter-se em pé sozinho, mas levará alguém para o ajudar a } \\
\text { ficar direito. }\end{array}$} \\
\hline & em seu feit'ajuda de si, & & & \\
\hline & mais levará, per quant'oí, & & & \\
\hline & quem lh'0 dereito sosterrá? & & & \\
\hline
\end{tabular}

a sua atividade trovadoresca, certamente iniciada ainda no reinado de D. Dinis, deve ter-se prolongado até meados do século XIV. Ainda vivo em 1362, terá morrido um pouco antes de Abril de 1364 (já no reinado de D. Pedro I), estando sepultado no Mosteiro de São Vicente de Fora" (Oliveira, 1993a).

5 Aparato crítico: (1) preito - questão judicial; En L. - optamos por modernizar a grafia nas duas edições, principalmente a nasalização e as letras ramistas; don foã CBN, CV; Don Joam Br.; Don Foan L.; (2) casto CV, caston CBN - questão. Admitimos a pontuação de Lapa com um meestre, há gram castom; Lop. suprime a vírgula por entender que o preito não é com o mestre, mas sim algum outro preito que tem em tribunal, isto é, D. Foão tem grande castom com um dos mestres de leis; (3-5) L. lê: "e o mestre imagina aquilo que é muito contrario ao direito"; (5) tan cox ar, o pre quamt'eu uy Mdo.; (7) decaer - cair e decair; de queera $\mathrm{CBN}, \mathrm{CV}$; decaerá $\mathrm{Br}$.; (8) decae palavra trissilábica (métrica) L.; (10) demandar - procurar; (12) eu ssen $\mathrm{CBN}$; au'ida CV; (12) deirito CBN, dereito CV, direito $\mathrm{Br}$ - não se trata de metafonia, mas erro provável do escriba; (15) ca-pois; (16) que Ih'é cajom - que lhe acontecerá uma desgraça (passará vergonha); cajon - "desastre, descrédito" L.; (17) leterados - alfabetizados, instruídos; (19) deato CV, dereyto CBN (20) des ali - desde esse momento. 


\begin{tabular}{|c|c|c|c|c|}
\hline \multirow{7}{*}{15} & Ca o meestre entende já, & A & (+) Epíteto-mestre & \\
\hline & se decaer, que lh'é cajom & $A p / J$ & $\begin{array}{l}\text { (-) Epíteto - apreciação } \\
\text { cajom }\end{array}$ & (-) julgamento - dado pela metonímia efeito pela causa. \\
\hline & antr'os que leterados som, & & & \\
\hline & onde vergonha prenderá & & & \\
\hline & d'errar seu dereito assi; & $\mathrm{J}$ & (-) Comentário & (-) direito em sentido jurídico, e pé direito \\
\hline & e quem esto vir, des ali, & & & \\
\hline & por mal andante 0 terrá. & $\mathrm{J}$ & (-) Relacional & \\
\hline
\end{tabular}

Quadro 2. Análise da avaliatividade de CBN, 1303; CV, 908.

A caracterização negativa do alvo do chiste fica consubstanciada na própria relação com a coxeadura do magistrado. Logo, notamos a construção de um paradigma ideológico na imagem caricaturizada da pessoa portadora de alteridades, neste caso, um homem manco. Piza (1991: 17-21), analisando resumos coletados por Amaral (1991: 35), apresenta três imagens predominantes da personagem portadora de algum tipo de deficiência física, entre outras:

1 - na maioria dos resumos que fazem referência direta à presença destas personagens, elas surgem como aquelas (especialmente as personagens humanas) que perseveram num discurso de resignação, capaz, por vezes, de valerlhe o prêmio da "normalidade", milagrosamente conseguida;

2 - o diferente/deficiente depende da interposição de um "normal" entre si e o mundo, para viabilizar sua existência;

3 - o diferente feliz é o diferente exilado. Uma existência plena só é possível fora do universo da "normalidade".

No caso da cantiga de Estêvão da Guarda, há alguns aspectos que dramatizam mais o quadro traçado por Piza (1991), entre eles:

- O personagem portador de alteridade não é produto ficcional, a não ser a sua representação, que pode ser exagerada;

- À época das cantigas galego-portuguesas, ainda não havia qualquer intenção de estabelecer caráter de normalidade àqueles portadores de alteridades, mesmo quando ocorria intervenção de tratamento; e

- O objetivo dos remoques não buscava modalizar ou ressignificar a crítica. O jogo de palavras muitas vezes servia somente ao propósito canônico do sirventês, para intensificar o riso, isto é, a sociedade não estava em busca de uma espécie de 'reparação social', pelo contrário, construía-se lentamente um abismo social entre os considerados 'normais' e os 'anormais'. 
É importante fazer a ressalva de que o processo de estabelecimento do valor de 'normal' não deve ser ingenuamente atribuído exclusivamente à ótica de Estêvão da Guarda ou aos demais trovadores de então. Uma análise cautelosa da tradição ideológica do preconceito deveria levar em consideração o seu contexto de produção, uma vez que, aplicada a máxima popularizada por Max Weber, os trovadores também são homens de seu tempo. Assim sendo, estavam sujeitos às forças das diversas dimensões contextuais que os cercavam à época: situação, cultura e ideologia da Península Ibérica medieval.

A teoria da avaliatividade, na perspectiva do presente estudo, apenas fornece as lentes necessárias para verificar indícios da construção de valores morais e éticos. No entanto, a avaliação de tais valores dependerá invariavelmente da visão crítica do leitor/analista. "O cientista que julga colocar-se acima dos fatos para compreender a história ou a sociedade, revela não a verdade objetiva que almeja, mas os preconceitos de seu tempo" (Alves, Rabelo e Souza, 2014: 1).

A se considerar a evolução histórica dos conceitos ora analisados, a diacronia oferece maiores desafios na análise do fenômeno (preconceito e estereotipação), motivo pelo qual procuramos entendê-lo por uma visão hermenêutico-fenomenológica, "que guarda traços que a aproximam da complexidade, dentre eles, a possibilidade de vislumbrar um fenômeno de ângulos diversos, porém complementares" (D'Esposito e Costa Neves, 2015). A esse respeito, Costa Neves (2011: 77) entende que

sob o olhar da complexidade, a realidade é tida como em constante mudança, dinâmica, multifacetada, sendo concomitantemente estável e instável. [...] não trabalhamos com hipóteses, não tentamos reduzir as possíveis variáveis, e não buscamos uma desejada linearidade de causa e efeito.

A realidade do preconceito e a dicotomia da normalidade foram, portanto, também, e não só, resultado das mudanças sociais, históricas e culturais da Idade Média. Por exemplo, o crescimento do Cristianismo na Península também trouxe efeitos antagônicos, tendo a doutrina cristã cultivado valores voltados para a caridade humana e amor ao próximo e, paralelamente, a pregação de uma ideologia segregacionista. Por exemplo, ordens dos frades menores, como a dos franciscanos e beneditinos, ajudaram na doutrinação da remissão dos pecados pela abnegação e ajuda ao próximo, em especial 
os debilitados, doentes e portadores de alteridades. A Igreja passou a apoiar iniciativas nesse sentido ${ }^{6}$ (ver Silva, 1987).

Ao mesmo tempo, ao progredir na Idade Média (entre os séculos V e XV) -lembrando que a cantiga recém analisada é de meados de 1310 - as referências históricas documentam a crescente associação de alteridades com magia e misticismo, ampliando noções de preconceito. Conforme Silva (1987), incapacidades físicas passam a ser fortemente associadas a forças demoníacas (estereotipação) e a Igreja Católica ajuda a consolidar certos 'padrões de normalidade'. A rejeição e a perseguição tomam vulto durante a Inquisição. Quando não eram mortos, os deficientes, multilados, portadores de deficiência e doentes (principalmente aqueles sobreviventes da hanseníase, peste bubônica, difteria e lepra) passavam a viver em completa marginalidade.

Dados históricos e testemunhais podem ser facilmente recuperados em documentos históricos, como os livros de linhagens, no entanto, a memória que a literatura ajudou a erigir se configurou numa grande barreira a ser vencida: um paradigma construído a partir de pressuposições ideológicas culturalmente construídas e de difícil superação. Ainda no século XXI, observamos resquícios de segregação, preconceito, racismo e eugenia em algumas representações ideológicas na tradição literária. Para Guerra (2006), vivemos um momento de especial conflito ético e vemos discusões de temas segregatórios ressurgir com grande intensidade.

A seguir, apresentamos a análise da cantiga CBN, 1611; CV, 1144, única produção do trovador Estêvão Fernandes Barreto ${ }^{7}$ de que se tem notícia. $\mathrm{O}$ aspecto interessante dessa cantiga é que seu alvo é um cavaleiro gafo (leproso) e o Nobiliário $^{8}$ nos indica que um dos sete filhos do autor era, curiosamente, gafo.

6 Exemplos: Concílio de Calcedônia (451) e hospitais católicos como o Childebert (Lyon).

7 "Trovador português, ativo nos finais do século XIII. Originário de uma linhagem de infanções de Entre-Douro-e-Minho, era filho de Fernão Gomes Barreto, cavaleiro documentado na corte de Afonso III, e de Sancha Pais de Alvarenga, sendo primo dos trovadores João Velho e Fernão Rodrigues Redondo. Era também cunhado de D. Maria Rodrigues Chacim, que tinha sido barregã de D. Dinis. De Estêvão Fernandes Barreto diz ainda o Nobiliário do Conde D. Pedro (26S5) que casou em Santarém com Joana Esteves e nom casou como devera (como o nome da sua mulher parece indicar, tratar-se-ia uma burguesa da cidade). É exatamente em Santarém que o trovador está pela última vez documentado, em 1294, como testemunha de uma doação feita a D. Dinis pelo concelho da vila. Também a sua única cantiga conservada nos remete para estas mesmas coordenadas espacio-temporais" (Oliveira, 1993b).

8 Acesso em Livros de Linhagem, como o do Conde D. Pedro (Mattoso e Pedro, 1980). 


\begin{tabular}{|c|c|c|c|c|}
\hline & \multirow[t]{2}{*}{ CBN 1611, CV $1144^{9}$} & \multicolumn{3}{|r|}{ avaliatividade } \\
\hline & & Tipo & INSCRITOS & EVOCADOS \\
\hline$R$ & $\begin{array}{l}\text { Esta cantiga de cima fez Stevam Fernándiz } \\
\text { Barreto a um cavaleiro que era gafo e morava } \\
\text { em Santarém; e soem a ir em romaria a Santa } \\
\text { Maria; aa mão dereita do caminho está logo a } \\
\text { Triindade, e estava logo a gafaria a par dela. }\end{array}$ & J & $\begin{array}{l}\text { (-) Epíteto } \\
\text { (-) Epíteto }\end{array}$ & $\begin{array}{l}\text { (-) Lapa afirma que a rubrica "oferece suas dúvidas", mas define } \\
\text { o mote como "trata-se pois de um cavaleiro leproso, que fugia } \\
\text { a ser metido na Gafaria, e dum tal Fernão Dade, que espreitava } \\
\text { a ocasião para lá o internar". De fato, o próprio tom de anedota } \\
\text { representa uma avaliação evocada recuperada contextualmente. }\end{array}$ \\
\hline 1 & [E]stêv[am] Eanes, por Deus mandade & & & \\
\hline & a Roi Paaes, logo este dia, & & & \\
\hline & [que] se quiser ir a Santa Maria & & & \\
\hline & que se nom vaa pela Triindade, & & & \\
\hline \multirow[t]{2}{*}{5} & ca mi dizem que the tem Fernam Dade & & & \\
\hline & ciada feita pela gafaria. & J & (-) Epíteto & $\begin{array}{l}\text { (-) A avaliatividade se dá pelo significado de fundo construído } \\
\text { pela figuratividade. Segundo Lapa (1965: 207), "a alusão } \\
\text { parece clara: Rui Pais, como leproso, deveria recolher à Gafaria, } \\
\text { onde Fernão Dade, talvez um funcionário do Rei, o queria meter } \\
\text { à força, armando-the uma cilada" }\end{array}$ \\
\hline & & & & \\
\hline & \multicolumn{4}{|l|}{ Se a romaria fazer quiser, } \\
\hline & \multicolumn{4}{|l|}{ como a sempre fazer [el] soía, } \\
\hline & \multicolumn{4}{|l|}{ outro caminho cate todavia; } \\
\hline \multirow[t]{3}{*}{10} & ca 0 da Triindade nom lh'é mester; & & \multirow[t]{3}{*}{ (-) Epíteto } & \multirow[t]{3}{*}{ (-) avaliatividade análoga ao refrão anterior. } \\
\hline & ca dizem que Fernam Dade lhe quer & \multirow[t]{2}{*}{ J } & & \\
\hline & meter ciada pela gafaria. & & & \\
\hline & \multicolumn{4}{|l|}{ E cada que el vem a Santarém, } \\
\hline & \multicolumn{4}{|l|}{ sempre aló vai fazer romaria; } \\
\hline \multirow[t]{2}{*}{15} & \multicolumn{4}{|l|}{ e da Triindade, per u soía } \\
\hline & d'ir, mandade que se guard'el mui bem, & J & & $\begin{array}{l}\text { (-) o comentário de aviso para precaução consolida um paradig- } \\
\text { ma de perseguiç̃ão comum pela qual passavam os doentes de } \\
\text { lepra, ao menos os nobres, para internação. }\end{array}$ \\
\hline & ca dizem que Fernam Dade lhe tem & J & & $(-)$ o mesmo. \\
\hline & ciada feita pela gafaria. & & & \\
\hline
\end{tabular}

Quadro 3. Análise da avaliatividade de CBN, 1611; CV, 1144.

9 Aparato crítico: (Rubrica) soer - costumar; gafaria - hospital para leprosos; a rubrica só vem completa no CBN; (1) Ss teneans CBN, Steveans CV, [Don] L. - discordamos da leitura de Lapa, que identifica o personagem como D. Estevão Anes, chanceler do Rei D. Afonso III, de Portugal. Apesar de imprecisa, parece-nos acertada a análise de Oliveira (1993b) quanto à identidade deste cavaleiro. Diz ele haver duas hipóteses: (a) tratar-se de D. Estêvão Anes Brochardo, arcediago de Santarém entre 1293 e 1298 e privado de D. Dinis a partir de 1296, tornando-se posteriormente bispo de Coimbra, e que era primo direito de Fernão Dade, citado pela cantiga; ou (b) Estêvão Anes de Paiva, que aparece como testemunha, ao lado de Fernão Dade, numa doação a D. Dinis assinada também pelo trovador. $O$ referido documento coloca os dois personagens no mesmo contexto. Some-se a isso, a consideração de que Estêvão Anes de Paiva era primo de Rui Pais de Paiva, também mencionado no segundo verso da cantiga, sendo ambos netos do prolífico trovador João Soares de Paiva. Estando certa esta interpretação de Oliveira (1993b), datado o testamento de Fernão Dade em 1295 e "estando o trovador atestado em Santarém no ano anterior, a cantiga deverá ter sido composta por esta data"; (2) paciez CV, paaez CBN - Pizarro (1999: 424 e 426) aponta a possibilidade de ser Rui Pais Bugalho, "que o Livro de Linhagens do Conde D. Pedro nos 
Apesar do tom bem-humorado da cantiga, a marca ideológica está presente na estereotipação do gafo. Na verdade, o humor é uma das formas silenciosas pelas quais o preconceito se instaura. Para Goffman (2009: 67), "caricaturas, piadas e lendas populares revelam, de maneira pouco séria, as fraquezas de um membro estereotípico da categoria.”. A bem da verdade, a caricatura estereotipada do portador de alteridade, o leproso nesse caso, imputa uma ambivalência ideológica semântica com valor na anormalidade. Nesse caso, até mesmo o fato do trovador ter um filho nas mesmas condições, revela o que Goffman (2009) chama de 'auto-alienação'.

O estereótipo construído pelo humor rapidamente se difunde na sociedade, mesmo quando não estabelecido em princípios de razoabilidade e lógica. $\mathrm{Na}$ Idade Média, por exemplo, a homossexualidade também era comparada a uma enfermidade ${ }^{10}$, a mais das vezes ligada a razões espirituais e pela associação com o, como referenciavam, "Demo". Tal atitude, amplamente considerada como preconceituosa e reprovável, perdurou ainda por alguns séculos na literatura de alguns autores que encontraram nesta tradição a amplificação desse tipo de representação estereotipada da sociedade.

Nesse ponto em especial, justifica-se uma pequena digressão da discussão do tema da cantiga para abordar brevemente a questão da homossexualidade -à época também tratada como alteridade e estereotipada-. Por exemplo, um conjunto de sátiras direcionadas a D. Estevam ${ }^{11}$ faz alusões, mais ou menos encobertas, de suas feições e aspectos homossexuais, referem o seu alegado mau caráter e também seus problemas de visão. Em geral, nessa antologia, o problema de visão (miopia) é considerado no mesmo nível do homosse-

diz "ter sido bom cavaleiro e privado d'el rei D. Dinis (71B3)". Mantemos a leitura de Oliveira (1993b) pelo amparo em contexto e documentos; (4) triscare CV, trijdade CBN, trindade Br. (5) Fernam Dade - segundo Pizarro (1999) é filho de Martim Dade, um conhecido alcaide de Santarém. (6) ciada - cilada; (8) soía - costumava, referência a uma romaria que costumava fazer para a cidade de Santarém; (10) seer mester - ser conveniente; (14) alo CBN, CV - ali ou lá, advérbio ainda utilizado na língua galega; (15) $u$ - onde.

10 São cerca de quarenta produções que representam essa temática e demandam estudos mais aprofundados.

11 Vasconcelos (1911) identifica este D. Estêvão como D. Estêvão Anes, o poderoso chanceler de Afonso III. Para isso, baseia-se na data provável das composição deste ciclo de cantigas. É de crer que Estêvão Anes, à época, ainda não tinha atingido o protagonismo que alcançaria posteriormente na corte de Afonso III. O texto dos cantares evidencia um íntimo relacionamento entre - Bolonhês e o alvo das chufas. Oliveira (2006) reforça a ligação entre Estêvão Anes e Afonso III, no entanto, não propõe nenhuma identidade alternativa para este $D$. Estêvão, cujo antroponímico e identidade permanecem desconhecidos. 
xualismo, o que comprova, lamentavelmente, uma associação entre orientação sexual e alteridade de saúde. Em um de seus cantares, por exemplo, Rui Queimado diz que, por pecar, D. Estevam ouve atentamente o sermão na Igreja, pois não enxerga. Noutro momento, refere-se a uma certa hipocrisia, dada pelo contraste entre o comportamento de D. Estevam na igreja e suas atividades noturnas, como se a cegueira fosse um embuste para a 'prática homossexual', então recriminada (CBN, 1386; CV, 995):

Oí dizer por vós que há sazom que vedes [já] quanto, pois me deito e dormesco e dórmio bem a feito, que assi veedes vó'lo artom; e assanhei-m'eu e dixi por en:

- Confonda Deus quem cego chama quem assi ouve come vó'lo sarmom. ${ }^{12}$

O grupo de trovadores alfonsinos que desferiram dichotes a D. Estevam é grande, entre eles, João Soares Coelho ("Dom Estêvam fez sa partiçom”, "Quem diz de Dom <Stêvam que nom vê bem" e "Dom Estêvam, que Lhi nom gradecedes"), Mem Rodrigues Tenoiro ("Dom Estêvam achei noutro dia"), Airas Peres Vuitorom ("Dom Estêvam diz que desamor", "Dom Estêvam, tam de mal talam" e "Dom Estêvam, eu eiri comi").

Além do homossexualismo, outros aspectos do comportamento humano também foram vistos como alteridades e estigmatizados pelo preconceito, embora ainda seja desconhecida a exata noção do quanto a representação estereotipada em obras mais antigas tenha se extendido no intelecto de obras posteriores. É certo, no entanto, que: (Nelson, 2009: 4)

a tendência para simplificar as coisas tem nos levado a descartar algumas das características presumidas de estereótipos e preconceito que foram essenciais para conceituações iniciais [...] que incluem imprecisão, negatividade e supergeneralizações. [...]

Estereótipos são problemáticos porque são negativos, imprecisos e injustos eles seriam simplesmente parte do estudo da percepção da pessoa.

12 Paráfrase: Ouvi dizer por vós que há uns tempos / que vedes [já] um pouco, pois me deito / e adormeço e durmo um sono alto (altas horas da noite) / que assim vedes vô-lo arteiro (aqui no duplo sentido de homem mal, fezendo referência às rondas noturnas de D. Estêvão) / e me zanguei e disse por isso: / - Castigue Deus quem cego chama quem / assim ouve como vô-lo sermão (por pecar, ele ouve depois atentamente o sermão). 
Para Czopp (2008), mesmo quando positivos, os estereótipos são essencialmente negativos ou trazem consequências negativas. A literatura, particularmente quando trata de questões de alteridade, ressurge na modernidade como um estandarte da resistência à mudança de paradigmas. Jauss (1994: 3) propõe que a renovação da história literária exige a "eliminação dos preconceitos do objetivismo histórico e fundação estética tradicional da produção e da representação" para uma "crítica reflexiva do autor". Nessa linha, nossa análise apresentou estereótipos construídos com base em complexos ideológicos de preconceito cristalizados e evidenciados na análise da avaliatividade realizada no corpus. Reitera-se que, embora adstritas às duas cantigas analisadas, as inferências possíveis, a partir dos resultados obtidos, apontam na direção de representações análogas nas demais cantigas da antologia (Quadro 1). Extensivos estudos são bem-vindos no sentido de ampliar, ratificar ou retificar as discussões analíticas ora apresentadas.

\section{Considerações Finais}

O presente estudo revelou que aspectos de alteridade, desde o início de nossa tradição literária, se desenvolveram fortemente no contexto do pensamento medievo. A semântica da avaliação demonstrou a dimensão negativa na qual estavam envoltos os personagens portadores de alteridades retratados nos cantares; ridicularizados pela dissonância com o conceito generalista de 'normal'. Além disso, a maior presença de avaliação implícita (avaliatividade evocada) potencializa o poder persuasivo dos cantares, principalmente pela via do humor. O processo de 'auto-alienação' também ficou demonstrado pelo enquadre dos trovadores nos cânones de normalidade forjados no ideário do catolicismo do medievo, o modelo teocêntrico e uma doutrina soteriológica que segregou o portador de alteridade como anormal na representação na literatura trovadoresca.

Por fim, concluímos buscando apoio nas considerações de Kaës e Werneck (1997: 139), para quem o preconceito está alicerçado no que chama de 'falta de formação', isto é, um "processo silencioso, lento, progressivo e cumulativo de noções inadequadas sobre temas-tabu". Portanto, a compreensão de como se deu o processo de representação do preconceito e estereotipação na época medieval ibérica, da qual somos herdeiros culturais, é o primeiro passo para o desenvolvimento do pensamento crítico de leitores e 
escritores de nosso tempo sobre certa herança ideológica, a qual, trazida para o nível da consciência, contribui na missão de uma reparação ética e social tão necessária para o desenvolvimento humano.

Ulisses De Oliveira Universidade Federal de Mato Grosso do Sul (UFMS)

\section{Referências bibliográficas}

Allport, Gordon. 1962. "Prejudice: Is it societal or personal?", em fournal of Social Issues, v. 18, nº 2, pp. 120-134. DOI https://doi.org/10.1111/j.1540-4560.1962. tb02205.x

Alves, Paulo César; Rabelo, Miriam Cristina e Souza, Iara Maria. 2014. "Hermenêutica-fenomenológica e compreensão nas ciências sociais", em Sociedade e Estado, v. 29, n ${ }^{\circ}$ 1, pp. 181-198. DOI http://dx.doi.org/10.1590/S010269922014000100010

Amaral, Lígia Assumpção. 1991. "Discriminação e estereótipos. Ciclo de Debates sobre Deficiência Visual". Em $O$ portador de deficiência visual e a sociedade. São Paulo. Mesa Redonda, São Paulo: PRO-DV.

Braga, Joaquim Teófilo Fernandes. 1978. O cancioneiro portuguez da Vaticana. Florida: Library of Alexandria.

Brito, Danilo Lopes; Bona, Fabiano Dalla. 2015. "Sobre a Noção de estereótipo e as imagens do Brasil no exterior", em Revista Graphos, v. 16, n. 2, pp. 15-28. http://www.periodicos.ufpb.br/index.php/graphos/article/view/23725/13021 [Consulta: 15/12/2017].

Ceschin, Humberto Leonardi. 2004. Poesia e História nos Cancioneiros Medievais: O Cancioneiro do Infanção. São Paulo, FFLCH/USP.

Christie, Frances e Martin James R. (eds.). 2005. Genre and institutions: Social processes in the workplace and school. London: A\&C Black.

Costa Neves, Rogério. 2011. A discussão de assuntos complexos na perspectiva de professores e alunos: the road (not) taken (tese de doutoramento). Programa de Estudos PósGraduados em Linguística Aplicada e Estudos da Linguagem. Pontifícia Universidade Católica, São Paulo. https://tede2.pucsp.br/handle/handle/13499 [Consulta: $15 / 12 / 2017]$. 
Czopp, Alexander M. 2008. "When is a compliment not a compliment? Evaluating expressions of positive stereotypes”, em Fournal of Experimental Social Psychology, v. 44, n², pp. 413-420. DOI https://doi.org/10.1016/j.jesp.2006.12.007

De Oliveira, Ulisses. 2014. A crítica ao poder em textos líricos dos séculos XIII, XVII e XX: um enfoque sistêmico-funcional. São Paulo: PUC-SP

D’Esposito, Maria Eugenia Witzler e Costa Neves, Rogério. 2015. "Pesquisando a partir da perspectiva da complexidade na área de linguística Aplicada”. em DELTA: Documentação e Estudos em Linguística Teórica e Aplicada, v. 31, nº 1, pp. 239259. DOI http://dx.doi.org/10.1590/0102-44500782365419818

Eggins, Suzanne e Slade, Diana. 2005. Analysing casual conversation. Sheffield (UK): Equinox Publishing Ltd.

Fairclough, Norman. 2003. Analysing discourse: textual analysis for social research. London/New York: Routledge.

Figueira, Emílio. 2000. "As pessoas com deficiências no contexto da literatura infanto-juvenil e didática”, em Mimesis, v. 21, n 1, pp. 39-52. https://secure.usc. br/static/biblioteca/mimesis/mimesis_v21_n1_2000_art_03.pdf [Consulta: 15/12/2017].

Guerra, Andréa Trevas Maciel. 2006. "Do holocausto nazista à nova eugenia no século XXI”, em Ciência e Cultura, v. 58, n 1, pp. 4-5. http://cienciaecultura.bvs. br/scielo.php? script=sci_arttext\&pid=S0009-67252006000100002 [Consulta: 15/12/2017].

Goffman, Erving. 2009. Stigma: Notes on the management of spoiled identity. London: Simon and Schuster.

Halliday, Michael Alexander Kirkwood. 1985. "Part A". Em Language, context, and text: Aspects of language in a social-semiotic perspective (M. A. K. Halliday e Ruqaiya Hasan). Oxford: Oxford University Press, pp. 1-49.

Halliday, Michael Alexander Kirkwood. 1994. An Introduction to Functional Grammar. (2aed.). London: Edward Arnold.

Herculano, Alexandre. 2014. História de Portugal. Lisboa: Ediçoes Vercial.

Hyland, Ken. 1998. Hedging in scientific research articles. Amsterdam: John Benjamins.

Iedema, Rick; Feez, Susan e White, Peter R. 1994. "Media literacy" Em Sydney: Disadvantaged schools program. NSW Department of school education. 
Jauss, Hans Robert. 1994. A bistória da literatura como provocação à teoria literária. São Paulo: Ed. Ática.

Kaës, René e Werneck, José de Souza e Mello. 1997. O grupo e o sujeito do grupo: elementos para uma teoria psicanalítica do grupo. São Paulo: Casa do Psicólogo.

Lapa, Manuel Rodrigues (ed.). 1965. Cantigas D'escarnbo e de mal dizer. Lisboa: Editorial Galaxia.

Laplatine, François. 2003. Aprender Antropologia. São Paulo: Brasiliense.

Le Goff, Jacques. 1986. A nova bistória. Paris: Edições 70.

Lopes, Graça Videira. 2002. Cantigas de Escárnio e Maldizer dos trovadores e jograis galego-portugueses. Lisboa: Editorial Estampa.

Machado, José Pedro e Machado, Elza Paxeco. 1949. Cancioneiro da Biblioteca Nacional: antigo Colocci-Brancuti. Lisboa: Biblioteca Nacional de Portugal.

Major, Ralph H. 1954. A bistory of medicine. Illinois: Charles C. Thomas Publisher.

Marques, Marcelo Pimenta. 2006. Platão, pensador da diferença-uma leitura do Sofista. Editora UFMG

Martin, James. 1992. English text: system and structure. Philadelphia/Amsterdam: John Benjamins.

Martin, James R. 2000. "Beyond exchange: Appraisal systems in English". Em Evaluation in text: Authorial stance and the construction of discourse (eds. Susan Hunston e Geoff Thompson). Oxford: Oxford University Press, pp. 142-175.

Mattoso, José Pedro. 1980. Livro de Linhagens do conde D. Pedro. Lisbon: Academia das ciências de Lisboa.

Nelson, Todd D. (ed.). 2009. Handbook of prejudice, stereotyping, and discrimination. Amsterdam: Psychology Press.

Oliveira, António Resende de. 1993a. "Estêvão da Guarda". Em Dicionário da Literatura Medieval Galega e Portuguesa (orgs. Giulia Lanciani e Giuseppe Tavani). Lisboa: Editorial Caminho.

Oliveira, António Resende de. 1993b. "Estevan Fernandiz Barreto". Em Dicionário da Literatura Medieval Galega e Portuguesa (orgs. Giulia Lanciani e Giuseppe Tavani). Lisboa: Editorial Caminho. 
Piza, Edith. 1991. "Imagens da deficiência na literatura infanto-juvenil: vícios e usos". Em $O$ deficiente e as diferenças na leitura infantil e juvenil: bibliografia (org. Márcia Cruz). São Paulo: Secretaria Municipal de Cultura de São Paulo - Seção de Bibliografia e Documentação, pp. 17-21.

Pizarro, José Augusto. 1999. Linhagens medievais portuguesas: genealogias e estratégias 1279-1325, vol. II, Porto: Centro de Estudos de Genealogia, Heráldica e História da Família da Universidade Moderna, pp. 424 e 426.

Reeve, C. D. C. 1998. Aristotle: Politics. Indianapolis: Hackett.

Sansone, Livio e Furtado, Cláudio Alves. 2014. Dicionário crítico das ciências sociais dos países de fala oficial portuguesa. Salvador: EDUFBA.

Sartre, Jean-Paul. 1978 [1946]. O existencialismo é um bumanismo. Trad. Vergílio Ferreira. São Paulo: Abril Cultural.

Scherer, Klaus R., Schorr, Angela e Johnstone, Tom (ed.). 2001. Appraisal processes in emotion: Theory, methods, research. Oxford: Oxford University Press.

Sequeira, Francisco Júlio Martins. 1959. Gramática bistórica da línqua portuguesa. Lisboa: F. Franco.

Silva, Otto Marques. 1987. A epopéia ignorada: a pessoa deficiente na bistória do mundo de ontem e de hoje. São Paulo: Centro São Camilo de Desenvolvimento em Administração da Saúde.

Silva, Sergio Gomes da. 2010. "Preconceito e discriminação: as bases da violência contra mulher", em Psicologia: ciência e profissão, v. 30, n³. DOI http://dx.doi. org/10.1590/S1414-98932010000300009

Todorov, Tzvetan. 1983. A conquista da América: a questão do outro. São Paulo: Martins Fontes.

Vasconcelos, Carolina Michaëlis. 1911. Lições de filologia portuguesa. Revista de Portugal.

Vivas, Diogo e Oliveira-Leitão, André. 2008. "A presença islâmica no Alentejo Litoral. Uma abordagem à luz da toponímia”. Em Actas do 1. ${ }^{\circ}$ Encontro de História do Alentejo Litoral. Sines: Centro Cultural Emmerico Nunes, pp. 221-230. 